\title{
Editorial
}

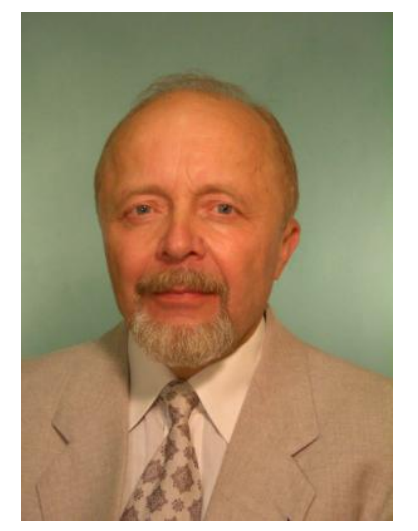

\section{Sustainability of Economic and Social Cohesion in the Extended European Union and Possibilities of Sustainable Growth}

\author{
Prof. dr. habil. Romualdas Juknys \\ Deputy Editor of the journal \\ Environmental Research, Engineering and Management \\ Vytautas Magnus University, Lithuania
}

Economic and social cohesion is considered the most important objective of the EU Treaty, therefore the equalization of living conditions and the quality of life are very important for successful EU integration. A fast growth in production and consumption was a characteristic feature of the new Central and Eastern European Member States of the EU $\left(\mathrm{EU}_{10}\right)$ before the current financial and economic crisis. However, per capita production and household consumption in these countries are still approximately twice lower than in the old EU Member States $\left(\mathrm{EU}_{15}\right)$, and a further catching-up growth should be expected. It is of paramount importance to ensure that the economic and social cohesion is not achieved at the expense of decreased environmental quality and increased input to climate change.

Analysis of trends in socio-economic indicators has shown that the highest rate of convergence in the extended EU is characteristic of prices, the lowest ones being in GDP and disposable income. A faster convergence in consumption expenditures rather than disposable income is characteristic of most new Central and Eastern European Member States of the EU. The main reason for this phenomenon is considered a fast increase in leasing, credits and other borrowing options before the current economic recession.

A fast increase in energy efficiency is considered a very positive feature of the $\mathrm{EU}_{10}$ development from the perspective of sustainability. Energy efficiency in the $\mathrm{EU}_{10}$ amounted only $56.6 \%$ of the $\mathrm{EU}_{15}$ level in 1995 and caught up to $77.5 \%$ in 2007 . Lithuania achieved the highest energy efficiency among EU $\mathrm{E}_{10}$ countries and reached $90 \%$ of the $\mathrm{EU}_{15}$ level as compared to35\% at the end of the Soviet period. From the point of sustainability, a very positive feature is that energy efficiency increased approximately 2.5 times during the entire 1991-2007 period and along with the $33 \%$ increase in GDP (in constant prices), the final energy consumption and emissions of green house gases almost halved and the emissions of acidifying compounds decreased three times during the period from the reestablishment of the independence up to the current economic crisis.

However, convergence in efficiency of human resources (labour productivity) is much slower. Thus, in the $\mathrm{EU}_{10}$ countries labour productivity is still almost twice lower than in the $\mathrm{EU}_{15}$. Cheap labour stimulates neither the implementation of modern technologies nor a faster labour productivity increase there. This leads to low salaries and unsustainable massive economic emigration from some new EU member states including Lithuania.

One of the key questions considering the sustainability of catching-up growth in the New Eastern European EU member states is whether they can reach the level of consumption and production in the old member states with an essentially lower environmental impact. The analysis of the current catching-up trends shows that a 
leaner use of resources and a smaller pollution than in the old EU member states are only possible on the consumption side. For example, over the1995-2007 period the amount of household waste in the EU $\mathrm{E}_{15}$ countries increased by $21 \%$, and on the contrary - despite a fast growth in the income it declined by $5 \%$ in the $\mathrm{EU}_{10}$ countries, currently it being about 1.5 times lower than in the $\mathrm{EU}_{15}$. What concerns the use of household energy per capita, it was approximately by one third higher in the $\mathrm{EU}_{15}$ countries in 1995 , and no convergence was detected up to the end of the analysed period. Traditions and habits of a leaner life in the new Eastern European member states may be expected to cause a markedly lower environmental impact related to consumption as compared to the old EU member states.

Looking from more general positions, it is necessary to note that a recent model of market economy is still based on the continuous growth of production and consumption. During the last decades market has rapidly saturated and consumption rather than production has become a main driving force of economy in developed countries. Despite the fact that most politicians and economists formally accept the sustainability ideas and understand such fundamentals of sustainability as impossibility of unlimited growth, the economy of developed countries is still based on a debt driven stimulation of consumption and production growth.

The financial and economic crisis has highlighted main weaknesses of such an approach and stimulated a search for new ways of development. Approaching the Rio+20 Summit, the main stream of proposals is oriented to the indispensable greening of current economy. To achieve this goal, different strategic documents have been put forward over the last (2011) year: the OECD green growth strategy, the EU growth strategy 2020, the EU plan for competitive low carbon economy by 2050 etc.

From the perspective of sustainability, there are lots of positive features in these strategic documents including the plans of a considerable cut in green-house gases emissions, enhancement of energy efficiency, replacement of fossil fuels, reduction in air pollution etc. However, these documents still consider the economic growth as an obligatory component of sustainable development, and the worst of it is that they do not even mention that infinite growth, no matter the colour - green or other, will be impossible in a finite planet.

At the same time, the economic crisis has stimulated the rebirth of the opposite ideas on the necessity of radical de-growth of consumption and production, emphasising that a political and social system in developed countries is not able to solve current complicated problems. Taking into account that sustainability of consumption and production is mainly characterized by their environmental impact, but not by the level of consumption and production itself, the concept of radical de-growth is unacceptable for several reasons. First of all, radical reduction in production and consumption not necessarily lead to reduction in an environmental impact. The next very important point is that the concept of radical de-growth neither fits in with market economy nor with representative democracy, and, in fact, it cannot be implemented peacefully without bloody social revolution resulting in unpredictable consequences. The sentence from the book "Prosperity without Growth" by T. Jackson fits well to summarise the situation: "growth is unsustainable, de-growth is unstable".

The necessity to reduce an ecological footprint of developed countries down to allowable limits in order to make space for faster economic growth of developing regions is evident. According to the experience of developed countries, an increase in efficiency of natural resources can, at its best, stop the growth in total use of resources and avoid a rebound effect. Taking into account that in developed countries more than two thirds of ecological footprint is related to the use of traditional energy, de-fossilisation of an energy sector and essential acceleration in the use of renewable energy are the most promising option. Since materials can be recovered, this option, if properly used, is able to reduce considerably the demand for newly extracted materials.

If the efforts to increase the efficiency of resources (both materials and energy), to accelerate the transition from fossil fuel to renewable energy, as well as much more intensively to reduce the demand for newly extracted materials, their recovery will be fundamentally strengthened and an essential reduction in the current ecological footprint of developed countries along with decelerating economic growth seem an attainable task. 